J. Lake Sci. (湖泊科学) , $2007, \mathbf{1 9}(5): 522-529$

http:// www. jlakes. org. E-mail: jlakes@ niglas. ac.cn

(C) 2007 by Journal of Lake Sciences

\title{
$15-20$ 世纪大陆泽与宁晋泊演变的影响因素分析”
}

\section{石超艺}

(华东理工大学社会与公共管理学院,上海 200237)

摘 要: 15 至 20 世纪,海河流域南系历史上著名的湖泊一一大陆泽和宁晋泊经历了从宽广到干涸的巨大变迁. 对于二泊 演变的原因,此前学者从未做过专门的分析和研究. 本文以明清时期丰富的历史文献为依据, 对影响湖泊演变的各大自 然和人文因子进行了深人探讨,得出如下基本结论: 海河南系水系格局不断变迁导致湖泊水源补给发生迅速改变, 是促使 湖泊相应发生显著扩张与萎缩, 并最终导致湖泊消亡的直接主要动因. 此外, 来自河流的泥沙淤积, 气候的干湿变化, 人 类拦水筑坝、占旺涸泊等活动加速了湖泊的演变与消涸.

关键词: 15 至 20 世纪; 大陆泽; 宁晋泊; 湖泊演变

\section{On the impact factors of the evolution of the Daluze and Ningjinpo Lakes during 15 th to 20th century}

\section{SHI Chaoyi}

( School of Social \& Public Administration, East China University of Science and Technology, Shanghai 200237, P. R. China)

\begin{abstract}
The Daluze and Ningjinpo Lakes, once the most well-known largest lakes in the plain in the southern part of the Haihe River valley, underwent dramatic evolution from vastness in the 15 th century to dry-up in about the middle of 20th century. As for why these two lakes dry up, however, there has been no focused analysis or study so far; this is the first endeavor on this topic. Based on rich historical information and archives originated from the Ming and Qing dynasties, this article gives an in-depth analysis to the key natural and human factors that affect the evolvement of lakes. Findings are: rapid changes in throughflows of inpouring rivers, caused by variations in water system distribution, are the most direct and prominent driver of the evolution of these lakes, resulting in significant expansions and shrinkages and, ultimately, dry-up. Besides, factors such as variations in rainfall, sediment carried by inputting rivers, dikes, and reclamation of wetland alongside lakeshore also contribute to the evolution and dry-up of the lakes.
\end{abstract}

Keywords: 15th- 20th century; Lake Daluze; Lake Ningjinpo; lake evolution

海河平原南部自古就存在一片以大陆泽为中心的宽广湖群 ${ }^{[1,2]}$. 17 世纪初, 湖群演变为以大陆泽、宁 晋泊为主的两大湖泊, 并与海河平原北部的白洋淀、文安洼齐名, 分别称为南北二泊和东西二淀. 然而在 19 世纪后期,大陆泽与宁晋泊 (为行文方便,下文称“二泊”)迅速走向了消亡 ${ }^{[3]}$.

湿地大面积消亡所引发的资源与环境问题人所共知,册庸赘言. 目前人们不惜代价保护白洋淀, 就是 因为这片湿地的存在有着重大的意义. 然而就大陆泽和宁晋泊而言, 由于它们干涸已久, 又因为当地经济 地理区位相对偏远等原因,该区的水环境研究一直不太受人重视. 有关该区湖沼湿地的历史演变, 更是只 有少数几位学界前辈进行过通论性的研究或简介;尤其对于近代二泊的消失原因,现代学者尚未进行过深 人细致的分析和研究,一般就直接沿用古人的说法, 认为南泊消亡主要由于水源导出所致, 北泊消亡则主要 因为澽沱河的泥沙淤积 ${ }^{[1,2]}$. 
如今这里的水资源危机日趋严峻, 由水引发的环境问题大有波及京、津之势. 人们也很难断言, 这种危 机可以随着南水北调工程的竣工而得到显著的改善, 这不仅因为以农村为主的该区难以承受高昂的水 价 ${ }^{[4]}$, 也因为北调之水不可避免地将首先以满足北京等中心城市的需求为主. 因此解决我国北方水资源短 缺的难题仍然需要考虑其它多种途径. 为了增加有效水资源, 改善水环境, 近年来已有不少学者提出了利 用洪水资源人工恢复部分湿地的意见, “十一五” 规划也明确提出了将 “雨洪资源科学利用转变” 的建议, 这 可能为恢复宁晋泊与大陆泽地区的部分湿地提供了新的研究契机.

为了给流域水环境规划与整治提供相关的科学依据, 也为恢复平原湿地这一争论已久的论题起到一定 的基础性作用, 同时还为其他类似湖泊的整治多提供一种历史的经验和教训, 笔者借助史料最为丰富的明 清历史文献作为主要依据 (主要包括方志、正史、一统志、舆地图、档案、实录、丛书和文集等), 对明代以来 该区纷繁复杂的水系格局变迁及湖沼湿地的具体演变过程进行了深人的分析和研究 ${ }^{[3,5,6]}$. 本文正是在完 成以上重要基础研究的前提下, 对直接影响南北二泊演变的主要因子进行综合探讨.

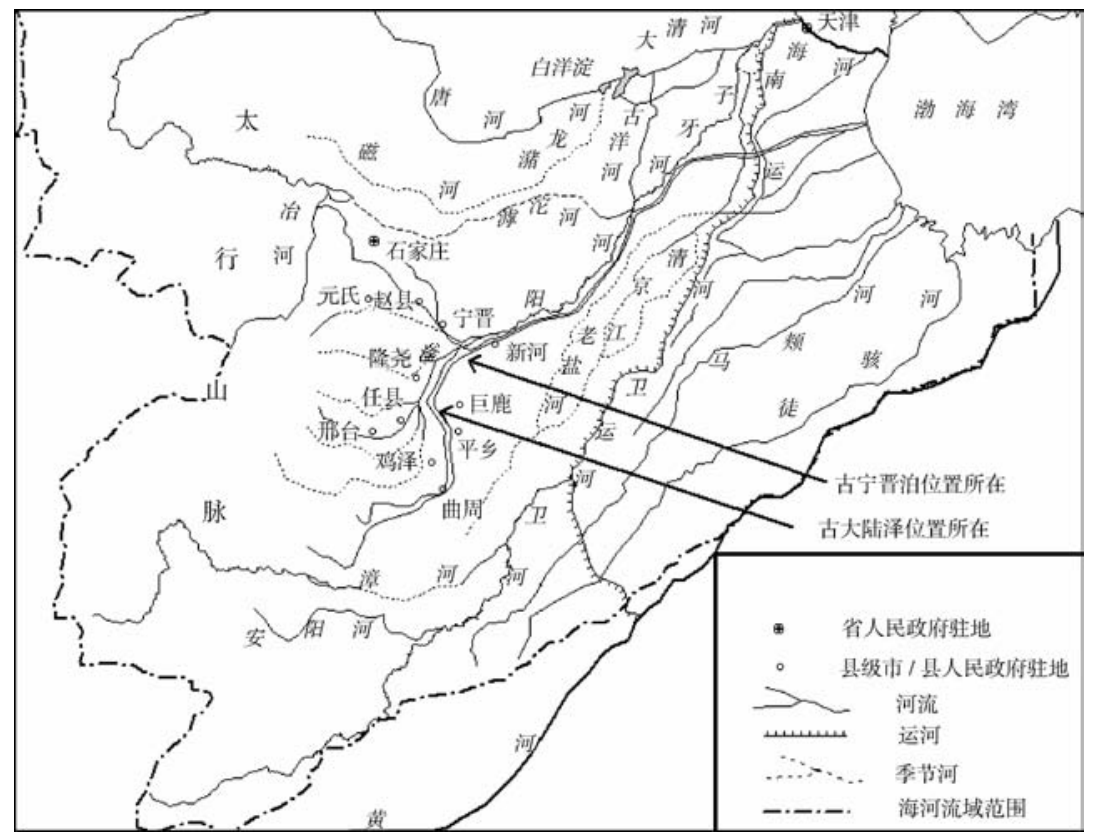

图 1 研究区现代水系面貌及古湖泊位置示意图

Fig. 1 Sketch map for the modern water system and the position of ancient lakes

文章研究的基本思路是: 以二泊演变的具体过程为背景, 对可能影响湖沼演变的各大自然和人文因子 进行深人分析, 并且根据各大因子变迁与二泊演变之间的相关关系, 判断这些因子对二泊演变的影响, 最后 做出综合结论.

\section{5 至 20 世纪大陆泽与宁晋泊的演变过程}

整个历史时期, 该区以大陆泽为中心的湖沼群总体上表现为不断萎缩的演变特征 ${ }^{[1,2]}$. 但自 17 世纪初 大陆泽逐渐解体成南、北两部分以来, 南部的大陆泽与北部的宁晋泊所经历的演变历程明显不同: 大陆泽主 要表现为持续萎缩; 宁晋泊则经历了由小到大, 由大到小的反复过程. 现将具体过程简述如下 ${ }^{[3]}$ :

16 世纪中期前后, 大陆泽南北长达 $50 \mathrm{~km}$ 左右, 东西广约 $15 \mathrm{~km}$, 形状貌似葫芦, 任县附近的南部较宁 晋附近的北部更为深广, 是湖泊的主体. 从 15 世纪到 16 世纪后期, 大陆泽一直是一个南起任县、北至宁晋 县的统一大湖. 
此后,随着湖泊的不断萎缩, 至 17 世纪初大陆泽逐渐分解成南、北两个相对独立的部分. 分解后的南 泊原本就是大陆泽的主体, 湖泊范围分明, 湖体比北泊更加深广, 因此承袭了湖泊分解前的名称, 仍称大陆 泽. 分解后的北泊则湖体平浅、散漫, 呈现一片河湖交错的景象,因主要位于宁晋县内, 另称宁晋泊.

然而从 17 世纪中叶开始, 宁晋泊急剧扩展. 虽然直到 1700 年, 大陆泽仍是海河南系平原上最大的湖 泊, 其次才是宁晋泊. 但此后二泊地位开始发展急剧变化: 大陆泽因持续快速萎缩, 至 1748 年南北仅约 17 $\mathrm{km}$, 东西仅约 $6 \mathrm{~km}$; 而宁晋泊则因持续快速扩张, 1809 年时已三倍于大陆泽. 到 1824 年, 大陆泽仅仅一息 尚存, 宁晋泊则已是漫漫巨浸.

到 1897 年, 大陆泽已基本消亡. 然而, 宁晋泊也发生了严重的萎缩. 1939 年, 宁晋泊在洪水季节纵横 仅余 $14 \mathrm{~km}$, 在枯水季节已不显泊形. 20 世纪五六十年代, 宁晋泊就完全走向了终结. 一处自先秦以来一直 存在的宽广湖沼群,至此成为历史往迹.

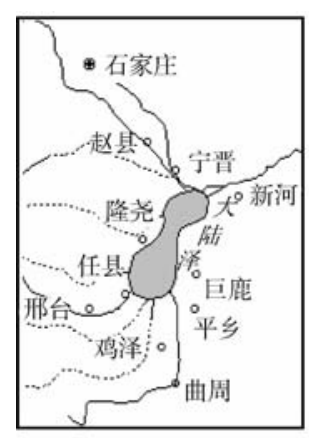

15-16 世纪后期

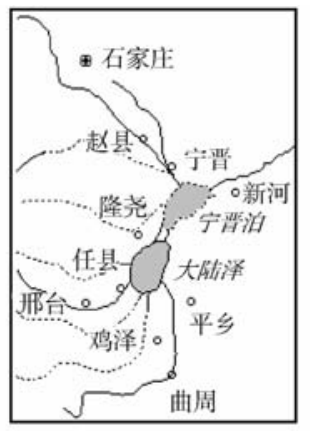

17 世纪中叶

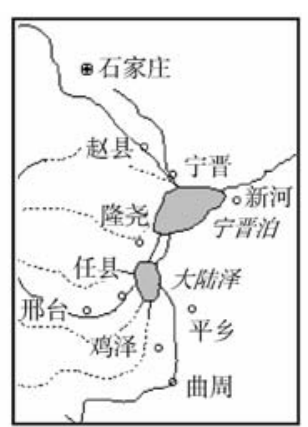

19 世纪初

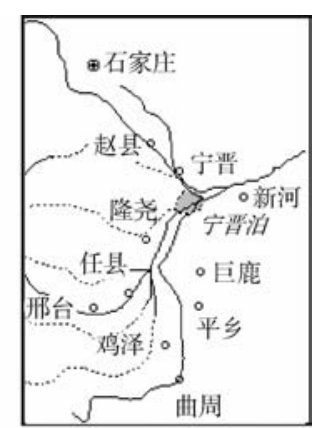

20 世纪初

图 2500 年来研究区湖泊演变示意图

（图中河流与政区代表现代状况; 虚线代表现代季节性河流,或过去河湖交错、轮廓不明的湖泊）

Fig. 2 Sketch maps for the evolution of the lakes in the past 500 years

\section{2 影响大陆泽与宁晋泊演变的主因子分析}

相对低洼的湖盆和充足的水源是形成湖泊的两大基本条件,影响湖盆形态和水源补给的各大因素一般 就是影响湖泊演变的主要因子. 大陆泽与宁晋泊是由古黄河与海河不断变迁造成差异堆积并与太行山东 麓之间共同作用形成的大型洼地 ${ }^{[1,2]}$. 近 500 年来, 该区新构造运动虽以沉降为主, 但并不十分强烈 ${ }^{[7]}$, 不 足以对湖泊的扩张产生较明显的影响. 因此,直接影响二泊演变的其他因子主要有径流补给、气候干湿状 况、泥沙淤积以及人类沿湖占垦. 以下对这些因子逐一进行深人的分析.

\section{1 地表径流补给}

2.1 .1 漳河、憈沱河的迁来徙去分别和大陆泽、宁晋泊的扩展与萎缩对应关系良好径流补给包括地表径 流和地下径流补给. 1958 年以前河北平原尚未大规模兴修水库, 也未大规模开采地下水, 地表径流是湖泊 占绝对地位的补给来源. 从现代流域格局来看,似乎只有滏阳河上游的支流能为湖泊提供地表径流补给, 但在历史时期, 海河南系最源远流长、水量最丰富 ${ }^{1}$, 同时也是变迁最频繁的两条大河, 亦即南部的漳河与 北部的滹沱河, 时常干涉大陆泽地区 ${ }^{[5,6,8]}$, 成为湖泊最重要的水源. 笔者在前人研究的基础上详细复原了 憈沱河与漳河的变迁过程, 发现从 14 世纪后期至 20 世纪初期, 南部的漳河与北部的滹沱河的迁来徙去分 别与南泊大陆泽和北泊宁晋泊的扩展和萎缩表现出良好的对应关系:

(1) 15 世纪, 澽沱河主流一直在南路, 漳河也主要行北路, 澞沱河与漳河都为湖泊提供了丰足的水源. 这时,大陆泽尚未分解, 是一个南起任县、北至宁晋的统一大湖泊.

(1) 河北省革命委员会水利局. 海河流域水文特征资料 (子牙河水系、南运河水系 (1907-1970)). 石家庄: 河北省革 命委员会水利局刊印, 1972:134-261. 
(2) 1517 至 1645 年, 憈沱河长期远离湖 区; 15 世纪后半叶, 漳河也逐渐以南流为主, 直 到 1573 年才重新回到北路. 这一时期, 湖泊发 生了重大的演变,即: 16 世纪末 17 世纪初大陆 泽发生了南北分解, 而且分解后, 南部大陆泽湖 体深广, 北部的宁晋泊湖体则相对平浅, 呈现出 一片河湖交错的景象.

当然,湖泊分解发生于漳河已返回湖区的 16 世纪末 17 世纪初, 而并非发生于澽沱河与 漳河同时离开湖区的 16 世纪中叶,一方面是因 为湖泊萎缩相对河流离去有一个滞后的过程, 另一方面还与气候的干湿变化、滏阳河上游较 好的水文条件, 以及明代前期滹沱河与漳河河 道泥沙含量相对较低、河道变迁次数较少有 关一一这些将在下文中详细述及. 但是河流离 去对湖泊萎缩的影响是显著的, 这一点还可以 从大量的史料记载中直接得到印证, 如隆庆 《赵州志》中就记载, 由于滹沱河的北徙, 湖泊 水位降低, “露出涸泊, ……亦可耕种” (1). 澽 沱河与湖泊的关系由此可见一斑.

(3) 1645 年, 澽沱河再度南徙, 直到 19 世 纪中叶, 它长期以南流为主. 在这一时期, 宁晋泊表现为持续扩张. 漳河从 1697 年起主流离开湖区, 1706 年后更是全部汇归卫运河, 此后不再回北路, 这以后大陆泽则表现为持续萎缩, 加之清代治理南北二泊主要 采取引导南泊之水泄人北泊, 从北泊泄洪的办法 (2),使南泊的持续萎缩与北泊的持续扩张表现得更为明显. 比如, 1700 年大陆泽仍大于宁晋泊,但仅仅到 1748 年, 宁晋泊就已三倍于大陆泽. 到 19 世纪二三十年代, 大陆泽就只有一小片水面尚且存在,至 19 世纪末则已完全干枯.

(4) 1850 年后,滹沱河逐渐北迁,1868 年更是全线北流,此后与宁晋泊再无干涉. 宁晋泊在 19 世纪二 三十年代仍是茫茫巨浸,但到 1897 年宁晋泊就几乎 “不显泊形” (3), 此后不断萎缩, 至 20 世纪初就迅速走向 了消亡.

（5）从 1958 年开始, 人们对海河流域进行了三次规模宏大的整治,易淤、易决、易徙的滹沱河与漳河从 此稳定在了单一的河道上——澽沱河被固定在北路, 漳河被固定在南路, 与宁晋泊和大陆泽地区极少有涉. 宁晋泊与大陆泽地区的湖沼湿地景观也不复存在,如今更是已成水资源严重缺乏的地区.

从以上澽、漳二河的来去与南北二泊的扩缩关系来看, 虽然湖泊的演变在明代相对于二河的来去往往 有一定时间的滞后, 但到了清代,这种对应关系就表现得极为一致了.

2.1 .2 涂阳河是湖泊最稳定的水源, 但入泊淦水在不断减少㴏阳河发源于太行山东麓, 上游支流繁多, 且 无一例外地流向大陆泽与宁晋泊地区, 虽然它的径流量远不及澽沱河与漳河, 但河道比较稳定, 是湖泊相对 稳定的水源 ${ }^{4}$. 然而进人清代以后, 随着人口的急剧增长 ${ }^{[11]}$, 人们开始大量占圼地肥水美的河流岸滩, 致使 河道淤塞加重, 河流生态恶化,一些常年河流演变为季节性河流, 甚至导致河流彻底干涸. 以元氏县为例:

(1) (明) 蔡森昭. 赵州志 (卷一) ·地里. 隆庆元年 (1567 年) 刻本.

(2) (清) 唐执玉,李卫,陈仪,等(修纂). 畿辅通志 (卷四十五) ·河渠. 雍正十三年(1735 年)刻本.

(3) (清) 孙传栻. 赵州属邑志(卷一) - 山川. 光绪二十三年(1897 年)刻本.

(4) 河北省革命委员会水利局. 海河流域水文特征资料 (子牙河水系、南运河水系 $(1907-1970)$ ). 石家庄: 河北省革 命委员会水利局刊印, $1972: 134-261$. 
元氏县境虽小,但在明代末年(17 世纪初)南有槐河、中有猪龙河、北有北沙河. 三条河流都属常年河流 ${ }^{(1)}$. 但是到了乾隆年间 (18 世纪), 只有槐河水经年不断, 其他两条都已成了季节性河流 (2). 到民国年间 (20 世 纪初), 占全县面积十分之二的三条大河已成不毛之地 ${ }^{3}$, 河流两岸尽是荒沙薄地. 滏阳河上游大小支流遭 受破坏,也使下游湖泊受到了影响.

同时,该区属灌溉农业区,水是关乎生计的宝贵资源. 明清时期, 尤其是清代,滏阳河上下游之间常常 为了抢水而争斗, 甚至发生流血冲突 ${ }^{[8]}$. 滏阳河上游为了拦水而修建的闸坝不断增加. 据笔者对相关史料 进行初步统计的结果, 仅任县、永年、南和、邢台、磁县、邯䣋、鸡泽六县,明清两代有史可查的闸坝就达 90 余 座. 由于以上原因,进人清代后,非洪水季节滏阳河上游对湖泊的补给在不断减少. 因此一旦滹沱河、漳河 离去, 湖泊更易急剧萎缩.

\section{2 气候干湿变化}

笔者利用与湖区地理位置最为接近的邢台地区五百年来旱涝等级资料作为依据 ${ }^{[9]}$ 一一这是反映研究 区气候干湿变迁的既有研究成果中分辨率最高的一项一一分析了研究区区域旱涝气候变迁的特点 (图 3 ).

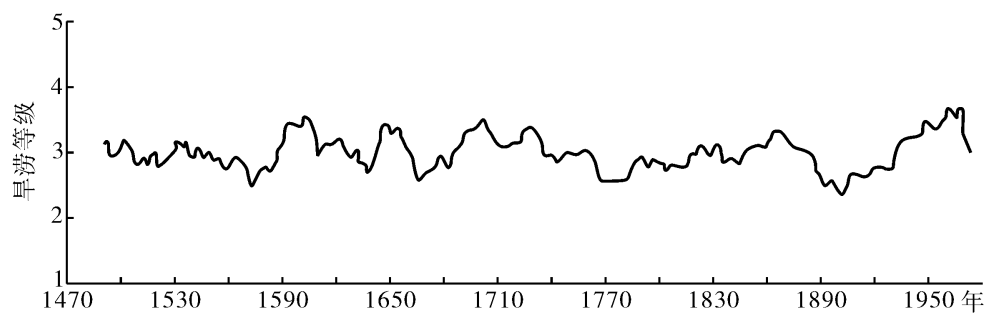

图 3500 年来研究区旱涝等级变迁 20 年滑动平均曲线

(旱涝等级 1 : 大涝; $:$ 涝; 3 :正常; 4 :旱; 5 :大旱)

Fig. 3 Moving average curve by 20 years of flood-drought rating in the past 500 years

从旱涝等级变化的 20 年滑动平均曲线来看, 大约在 $1581-1618$ 年、1636-1660 年、1680-1731 年经历 了三次大旱期. 可见, 大陆泽于 16 世纪末 17 世纪初分解成南北二泊与当地气候长期干旱不无关系. 18 世 纪中叶以后, 气候开始转湿, $1746-1810$ 年是一个明显的湿润期,这一时段, 北部的宁晋泊不断扩张. 显然, 气候的干湿变化会影响湖泊的演变.

但 $1746-1810$ 年间属湿润期,南部的大陆泽却表现为不断萎缩. $1870-1920$ 年也是一个明显的湿润 期,大陆泽与宁晋泊却同时走向消涸. 至 19 世纪末,南泊已经完全消失, 北泊也所剩无几.

可见,当澽、漳的离去与气候干旱,或澽、漳的到来与气候湿润叠加在一起时,大陆泽与宁晋泊的萎缩或 扩张将会在短期内发生更为显著的变化,甚至导致质的变迁. 但从 500 年间该区气候干湿变迁与二泊演变 的对应关系来看,气候显然不是促使湖泊发生巨大演变,导致湖泊走向消涸的主要原因.

当然,由于该区属典型的大陆性季风气候,降水量有明显的季节变化与年际变化,因此枯水期与丰水期 的湖泊水位差别很大, 遇到连年丰水或连年少雨, 湖泊蓄水量也会发生明显的改变. 如 1786 年, 大陆泽地 区连年干旱, 湖泊水位下降, 人们开脣土地达 450 余顷 (4), 而 1796-1801 年又遇上连年洪涝, 新开垦的地亩 又迅速被湖水所侵占 ${ }^{5}$. 也正是这种气候特征为占垦湖泊创造了客观条件, 从而加快了湖泊的淤积.

(1) 张慎学, 智铤. 元氏县志 (卷一) - 山川. 崇祯十五年 (1642 年) 刻本.

(2) 王人雄. 元氏县志 (卷首) - 與图. 乾隆二十三年 (1758 年)刻本.

(3) 王自尊,李林奎,武儒衡. 元氏县志・地理. 民国二十二年(1933 年)铅印本.

(4) 1 顷合 $6.667 \mathrm{hm}^{2}$.

(5) (清) 谢员麟, 陈智 (纂), (民国)王亿年, 刘书旂 (续修纂). 任县志 (卷一) - 河流. 宣统二年 (1910) 修, 民国四年 (1915) 续修铅印本. 


\section{3 泥沙淤积}

上文已述, 滹沱河与漳河是湖泊最重要的水源, 它们的迁来与徙走对湖泊的扩张与萎缩直接造成了显 著的影响. 但澽沱河与漳河历史时期一直是以善淤、善决、善徙而著称的大河,因此它们既是湖泊重要的水 源又是主要的沙源, 水来沙积,沙去水停,这使河湖间的关系更加复杂,主要表现为三种对立矛盾:

首先, 憈沱河与漳河给湖泊带来丰富水源的同时也带来了大量泥沙. 其次, 泥沙淤积抬高了湖床, 淤塞 了行洪河道, 妨碍了行洪, 雍高了湖面, 从而使湖泊从表面上看起来更显宽广. 再次, 一旦河流徙离, 淤高的 湖床尤易出露, 成为人们争先占垦的肥沃耕地, 湖泊也就迅速萎缩, 可一旦河水再次到来, 经耕作过的疏松 土层越易使湖床造成更严重的淤积.

正因为此,古人大都认为滹沱河与漳河都“不可以人泊”,并称“漳故人南泊,而穆家口塞;滹故人北泊, 而滏阳路夺” (1). 甚至称: “宁晋泊之淤、(㵚阳) 河之塞, 皆澽沱水之去来弥漫为之”(2). 可见漳、憈泥沙对区 域河湖系统造成了严重的影响. 也正因为此,此前学者直接引用古人观点, 将宁晋泊的消亡归处于滹沱河 泥沙的淤积 ${ }^{[1,2]}$. 虽然这种结论有失偏颇, 却是有一定道理的. 综合上文的研究分析和前人对整个历史时 期河流泥沙对湖泊影响的研究成果 ${ }^{[1,2]}$, 澽沱河的泥沙对湖泊的淤积虽然不能成为后来导致湖泊消涸的直 接主要动因, 但纵观历史, 泥沙淤积无疑是导致海河平原湖群逐步萎缩和分解的极其重要的原因之一.

河流泥沙对湖泊的影响程度,还会随着河流泥沙含量的高低和河道决徙的频度而变化. 就明清两代而 言, 随着太行山林木不断被开采 ${ }^{[11]}$, 流域水土流失日益严重, 澽漳二河决徙频率不断上升, 它们经由湖区时 对湖床的淤积程度也日益加重, 湖泊的演变进程亦不断加速: 明代前期, 滹沱河与漳河变迁改道的频率较 低, 滹沱河 15 世纪平均每 38 年才改道一次, 然而到了 17 世纪平均不到 5 年就会发生一次决徙 ${ }^{[4]}$. 漳河从 明代后期开始变迁频率更是一直居高不下 ${ }^{[5]}$. 明初至明正德十二年(1517 年), 憈沱河河道主要分为两股, 其中流经湖区的一股河道相当稳定, 百余年间有史可考的改道仅有一次, 1517 年滹沱河徙离了湖区,但直 到 1573 年大陆泽仍是南北相连的统一湖泊. 清代, 澽沱河在宁晋泊周边反复迁徙达 50 余次 ${ }^{[4]}$; 19 世纪 50 年代滹沱河开始北徙, 1868 年彻底离开湖区, 宁晋泊在 20 世纪初枯水季节就已不显泊形, 其间不过半个 世纪.

\section{4 占晆湖泊}

一般认为, 人类围湖造田、占垦泊地是导致湖泊迅速萎缩的重要原因. 但明清时期, 二泊周边的围乍主 要表现为受制于湖泊本身的扩缩.

整个明代, 冀南平原人口比较稀疏, 人地关系并不紧张, 有关占垦湖泊的史料亦比较少见. 但到了清 代, 随着人口的迅速增长 ${ }^{[10]}$, 情况开始有所不同. 民国《宁晋县志》转载了一篇有关清代宁晋泊周边地区人 们占垦宁晋泊湖岸的碑文 ${ }^{3}$, 碑文比较详细地记载了清代人们占剭湖泊的情况. 内容大致如下:

清初以前 (17 世纪中叶), 由于滹沱河长期远离湖区, 宁晋泊日渐萎缩. 宁晋泊“未经水占之间,一水一 麦, 地气肥美”,一些村民花重金购买了这些土地, “地价等于上”. 1645 年, 滹沱河逐渐以南流为主, 湖泊面 积因而大为扩张, 并造成“环泊地亩悉为泊占”. 原先购地的农民无可奈何只得 “赔纳钱粮”. 1671 年, 宁晋 县因被湖水淹没而豁免的土地赋额就达 1281.48 顷之多. 此后, 滹沱河长期人泊, 农民用重金购买的土地 长期付诸波涛, 只有在湖泊水位稍有下降的时候, 仍然各自认垦自己的土地. 1672 年至 1679 年湖水稍有回 落, 先前被淹的土地中有 530 余顷又重新被开旺出来, 可另外的 710 余顷仍然被湖水淹浸, 无法耕种. 因为 土地已经购买, 只好记下土地界址, 希望有朝一日湖泊干涸, 再来认领. 但 1684 年以后, 滹沱河北路淤塞, 河水全部南流, 湖面反而不断扩张, 此后百数十年一直如此. 由于土地长年被湖水淹浸, 农民只好逢干旱之 年, 泊水消减之时, 种些苇草, 以收薄利. 但时间一长, 官府以“泊地无粮”为由,饬令将其地产收回 “以充公 用”, 如不充为公用, 则需交纳赋税. 其他人也开始抢割湖中的苇草, 致使官民之间不断引发争端. 直到 1800 年才在一位姓廖的县令的主持下, 同意购买湖泊土地的地主们可以在不撤销其地权的条件下勉强免

(1) 万廷蘭, 戈涛. 献县志 (卷一) · 與地. 乾隆二十六年(1761 年)刻本.

(2) 苏毓琦, 伊承熙, 张震科. 宁晋县志 (卷一) ・封域. 民国十八年 (1929 年)石印本.

(3) 苏毓琦, 伊承熙, 张震科. 宁晋县志 (卷三) - 赋役. 民国十八年 (1929 年) 石印本. 
除赋税,这种频年争端才算基本结束. 其时,湖水浸占土地前后已长达 130 余年.

19 世纪中叶,澽沱河开始北徙,宁晋县的人们又开始争相抢占涸出的土地. 仅 1843 年, 宁晋县查核新 增的湖泊地亩 “东西自北鱼至史家嘴广约二十余里, 南北自南鱼至素邱、东汪、鱼台、赵庄长亦有三十余 里”. 然而由于地势低洼, 雨水又集中在夏秋两季, 新增的地亩十年九淹 ${ }^{1}$, 并没有给人们带来期冀中的收 成, 当然, 这已超出了本文的研究内容, 因此不再赘言.

可见,清代该区人们对湖泊的围庋虽然不可避免地会加剧湖泊的淤积,但明显受到湖泊进退的制约.

\section{3 结论和讨论}

\section{1 主要结论}

上文以湖泊演变的具体过程为背景, 对明清时期可能影响湖泊演变的各大因子:地表径流补给、气候干 湿变化、河流泥沙淤积和人类占层湖泊等的变化与湖泊演变之间的相互关系进行了深人具体的对比分析, 根据研究结果, 可得如下基本结论:

(1) 湖区周边的水系格局变迁与湖泊的演变显著相关, 尤其是滹沱河与漳河是否经过湖区分别成为宁 晋泊与大陆泽扩张或萎缩的直接主要动因.

(2) 湖区周边水系的水文状况是影响湖泊演变的又一重大因素. 憈沱河与漳河经过湖区时,河流的高 含沙量导致湖泊淤积加重, 行洪河道雍塞, 使湖泊的表面扩张与底部淤塞同时发生. 明清时期,随着滹、漳 河道变迁日益频繁,河流经由湖区时对湖泊的淤积也日益严重. 此外,随着滏阳河上游水源被大量拦截以 及河流本身的生态环境遭到日益严重的破坏, 使湖泊相对稳定的水源也受到了极大的影响,这在一定程度 上也加速了湖泊的萎缩.

(3)气候的干湿变化也是影响湖泊演变的重要因子之一. 无论是降水的季节变化还是年际变化,都会 使湖泊发生相应的变化, 尤其是当气候湿润与大河到来,或气候干旱与大河离去叠加发生时, 湖泊往往容易 发生质的变迁.

(4) 人类围湖造田与开垦涸泊对湖泊演变造成了一定的负面影响. 但是, 在当时的生产力条件下, 这种 开屋活动受制于湖泊本身的扩缩, 人们只能随水退而进,水进而退.

总之,500 余年的历史过程表明, 流域水系格局的改变是影响二泊演变的决定性因素, 流域水文状况 (主要包括河流泥沙含量和径流量) 是影响湖泊演变的重要原因, 气候干湿变化也对湖泊演变造成了一定 的影响. 简而言之, 水源的多塞才是决定宁晋泊与大陆泽存亡的关键. 因此, 如若考虑恢复部分湿地, 减少 流域水土流失固然重要,但合理分配水资源应该才是其中的关键和根本所在. 然而现实却是: 当前憈、漳、 滏的大部分水源被滞留在上游山区各大大小小的水库之中. 显然这也是人们必须反思的问题.

\section{2 讨论}

海河流域由于特殊的自然地理环境,历史时期一直是洪涝旱碱各种水害频发的地区. 然而在新中国成 立以后, 各种治水活动主要围绕防洪而进行, 却相对忽视了防旱. 如今流域水系面貌已经发生了重大的改 变, 上游众多水库与中游多条泄洪河道的建成,已使流域防洪条件大为改观. 然而,随着经济的发展, 人们 对水资源的需求急剧增长, 缺水矛盾日益突出. 水资源短缺已经成为阻碍区域经济、社会、生态可持续发展 的重要瓶颈. 比如由于上游水库的拦截,历史上的巨川滹沱河与漳河经常连年断流; 平原地区地下水超采 已经相当严重,致使许多用水大户不敢在此投资设厂; 人们的生产与生活也因缺水而受到了严重的影响 等等.

可是,为了满足中心城市的用水需求,该地区的缺水问题基本上很难通过增加上游来水得以缓解. 因 此, 只有增加有效水资源的总量才能真正意义上地缓解水资源危机, 增加河道生态用水, 填补超采的地下 水,改善区域水生态,并且缓解京、津、冀地区的分水矛盾.

新的“十一五”规划指出,未来五年,我国应该重视“三农”问题,重视区域统筹发展,重视洪水资源管 理. 笔者认为这是该区改善流域水系格局,改善流域水资源分配,考虑洪水资源化,甚至恢复部分湿地的重

(1) 苏毓琦, 伊承熙, 张震科. 宁晋县志 (卷一) - 川泽. 民国十八年(1929 年) 石印本. 
要契机.

当然,无论是恢复平原湿地,还是整治流域水环境, 都需要多学科、多领域的研究、交流与合作. 本文的 研究成果只能为流域水环境规划和整治提供一定的历史借鉴. 粗浅之见, 权当抛砖引玉, 希望引起学界同 仁的争鸣和关注.

致谢: 本文得到业师邹逸麟先生、张修桂先生和满志敏先生的指导, 谨致谢忱.

\section{4 参考文献}

１1］邹逸麟. 黄淮海平原历史地理. 合肥: 安徽教育出版社, 1993:197.

[2] 王会昌. 河北平原的古代湖泊. 地理集刊(第 18 号). 北京:科学出版社, 1987:79-83.

[3] 石超艺. 明代以来大陆泽与宁晋泊的演变过程. 地理科学, 2007,27(3):414-419.

[4] 胡润峰. “南水北调”的水价如何. 经济, 2003, (1):48-51.

[5]石超艺. 明以降滹沱河平原段河道变迁研究. 中国历史地理论丛, 2005,20(3):62-72.

６］石超艺. 明清时期漳河平原段河道变迁及其与 “引漳济卫” 的关系. 中国历史地理论丛,2006,21(3): $27-35$.

[7] 王若柏, 郭良迁, 韩慕康等. 河北平原水系密度与隐伏活动构造的关系. 地理学报, 2002, 57 (3),284 -292 .

[8] 王建革. 河北平原水利与社会分析 (1368-1949). 中国农史,2000,19(2):55-65.

[9] 河北省旱涝预报课题组编. 海河流域历代自然灾害史料. 北京:气象出版社,1985:113-128.

[10］葛剑雄主编, 曹树基著. 中国人口史 (明时期). 见: 葛剑雄主编, 曹树基著. 中国人口史(清时期).上 海:复旦大学出版社, 2001 .

[11] 刍逸麟. 中国历史地理概述. 厦门: 福建人民出版社, 2000:16-17.

[12] 海河志编撰委员会. 海河志. 北京: 中国水利水电出版社, 1997:93-104. 